\title{
COMUNICAÇÕES
}

\section{SCHISTOSOMA MANSONI: ON THE POSSIBILITY OF INDIAN BUFFALO (Bubalus bubalis) BEING EXPERIMENTALLY INFECTED}

\author{
Paulo Marcos Zech Coelho, Walter S. Lima \\ and Raimundo H. G. Nogueira
}

\begin{abstract}
Male Indian buffalo (Bubalus bubalis) calves were submitted to Schistosoma mansoni infection by percutaneous, oral and subcutaneous routes. No worms or eggs were found in four of the animals tested. Bubalus bubalis appears to be refractory for S. mansoni.
\end{abstract}

Key-words: Schistosoma mansoni. Indian buffalo. Experimental infection. Bubaius bubalis.

The literature shows that bovines can be found naturally infected with Schistosoma mansoni 1234 .

The Indian buffalo, by its behavior closely related to natural water collections, as well as its known role on the transmission chain of Schistosoma japonicum in Asia, could be also a potential host for $S$. mansoni.

This work was conducted to establish whether the Indian buffalo is susceptible to $S$. mansoni infection. It is important to mention that the Indian buffalo is reared in several regions in Brazil, in areas with or without $S$. mansoni transmission.

The experiments were carried out with 12 to 18 month-old male buffalos. In the first experiment, two animals were exposed to water suspension with 50,000 cercariae (LE strain) spilt on the abdominal skin. The animals were kept in dorsal decubitus for 1 hour. Forty days after infection, fecal examinations were performed 5 times a week, for a month. All the examinations presented negative results.

At 70 days after infection, the animals were injected with $5 \mathrm{ml}$ of heparin (Liquemine, Roche), intravenously, and after that they were sacrificed and perfused for worm recovery. Fragments of intestinal mucosa and liver were examined for eggs in tissues. No

\footnotetext{
Departamento de Parasitologia do Instituto de Ciências Biológicas e Departamento de Patologia da Escola de Veterinária da Universidade Federal de Minas Gerais.
}

This study was supported by FINEP and CNPq, Brazil. Address: Prof. Paulo Marcos Zech Coelho. GIDE/ICB/UFMG, CP: 2486 - 30161 Belo Horizonte, MG.

Recebido para publicação em 26/5/89. worms or eggs could be found in these animals. Details of these procedures were reported by Coelho et $\mathrm{al}^{2}$.

Two other animals were used to determine if the skin barrier is an important factor in the resistance to infection. It is well known that the skin of buffalos is thicker than that of bovine. For that purpose, one animal was deprived from water for 24 hours. After this period, a plastic receptacle containing 100,000 cercariae in water suspension was offered to the animal. The buffalo drank all the water suspension. This experiment was conducted to clear up a possible infection by cercariae penetration through oral mucosa. The last experiment was conducted to eliminate the skin barrier completely. So, one animal was infected with 30,000 cercariae, subcutaneously. Forty days after infection, the feces of the animals submitted to both procedures above described were examined five times a week, for a month, and no eggs could be found. At 70 days after infection, these two animals were sacrificed and submitted to the same techniques described in the first experiment. No eggs or worms were found in both animals.

It is possible to conclude that Bubalus bubalis is a refractory host to $S$. mansoni infection. Its natural resistance to infection semms not to be related to skin barrier.

\section{REFERENCES}

1. Barbosa FS, Barbosa I, Arruda, F. Schistosoma mansoni: Natural infection of cattle in Brazil. Science 138: $831,1962$.

2. Coelho PMZ, Nogueira RHG, Lima WS, Cunha MC. Schistosoma mansoni: experimental bovine schistosomiasis. Revista do Instituto de Medicina Tropical de São Paulo 24: 374-377, 1982. 
Comunicafãa. Coelho PMZ, Lima WS, Nogueira RHG. Schistosoma mansoni: on the possibility of Indian buffalo (Bubalus bubalis) being experimentally infected. Revista da Sociedade Brasileira de Medicina Tropical 22: 157-158, Jul-Set, 1989

3. Karoum KO, Amin MA. Domestic and wild animals naturally infected with Schistosoma mansoni in the Gezira Irrigated Scheme, Sudan. Journal of Tropical Medicine and Hygiene 88: 83-89, 1985.
4. Mayaudon TH, Power LA. Infestacion natural de bovinos (Bos taurus) de Venezuela por Schistosoma mansoni. Revista de Medicina y Parasitologia 23: 37-40, $1969 / 1970$. 